\title{
Real unit labour costs in Eurozone countries: drivers and clusters
}

\author{
Javier Ordóñez ${ }^{1 *}$, Hector Sala ${ }^{2}$ and José I Silva ${ }^{3}$
}

\author{
${ }^{*}$ Correspondence: \\ javier.ordonez@uji.es \\ Departament d'Economia, \\ Universitat Jaume I, Campus Riu \\ Sec, 12071 Castelló, Spain, Institute \\ of International Economics, \\ Universitat Jaume I and Universidad \\ Popular Autónoma del Estado de \\ Puebla (UPAEP), Puebla, Mexico \\ Full list of author information is \\ available at the end of the article
}

\begin{abstract}
We examine the trajectories of the real unit labour costs (RULCs) in a selection of Eurozone economies. Strong asymmetries in the convergence process of the RULCs and its components-real wages, capital intensity, and technology-are uncovered through decomposition and cluster analyses. In the last three decades, the PIIGS (Portugal, Ireland, Italy, Greece, and Spain) succeeded in reducing their RULCs by more than their northern partners. With the exception of Ireland, however, technological progress was weak; it was through capital intensification that periphery economies gained efficiency and competitiveness. Cluster heterogeneity, and lack of robustness in cluster composition, is a reflection of the difficulties in achieving real convergence and, by extension, nominal convergence. We conclude by outlining technology as the key convergence factor, and call for a wider strategy in labour market policies, which should be more oriented to promote the sources of productivity growth.
\end{abstract}

JEL Classification numbers: $\mathrm{F} 43 ; \mathrm{F} 62 ; \mathrm{O} 47 ; \mathrm{O} 52$

Keywords: Real unit labour costs; Eurozone; Real wages; Capital intensity; Technology

\section{Introduction}

Nominal convergence versus real convergence. Can the former last in the absence of the latter? Even if the Great Recession provides a negative answer, any state in the European Union (EU) desiring to join the Economic and Monetary Union (EMU) is still subject to meet the Maastricht criteria. These criteria, which were designed to ensure nominal convergence, ${ }^{1}$ entailed the implicit assumption that real convergence would naturally follow. This presumption has miserably failed. Not only have these countries lacked real convergence (in per capita GDP or unemployment rates), but "the strengthened financial and real connections across the EMU countries, instead of facilitating convergence (...) have magnified and mutually reinforced imbalances" (Croci and Farina 2012, p. 647).

Although it has become standard to refer to this slump as a 'sovereign-debt crisis', our view is that the rise in public deficits and debts, more than a governments' fail in the management of national fiscal policies, is the consequence of differences in competitiveness that generate real divergence and, therefore, growing account imbalances ${ }^{2}$. Our claim is that these imbalances, which were exacerbated with the EMU, were already present in latent form. This is contrary to Sinn's claim that "the lack of competitiveness was brought about by the euro itself" (Sinn 2014, p. 1). They reflected, indeed, a structural situation to which we implicitly refer when we divide the Eurozone into Core and Periphery

(c) 2015 Ordóñez et al. This is an Open Access article distributed under the terms of the Creative Commons Attribution License (http://creativecommons.org/licenses/by/4.0), which permits unrestricted use, distribution, and reproduction in any medium, provided the original work is properly cited. 
economies, acknowledging that the first group is far more competitive than the second one. ${ }^{3}$ Ultimately, this is what explains the real divergence we have witnessed since the inception of the euro, and it is also at the root of the differential intensity of the Great Recession in the Eurozone, once the sovereign-debt problem joined in in 2010.

In this paper we take the real unit labour cost (RULC) as a relevant indicator of competitiveness and, as such, as a driver of real convergence. We examine to what extent our hypothesis of latent divergence forces holds by clustering the RULC according to its performance in a selection of 11 Eurozone economies. This variable is defined as

$$
R U L C=\frac{\text { Real compensation per employee }}{\text { Real labour productivity }}
$$

which allows our analysis to be performed on the RULC as a whole, but also on its two main components ${ }^{4}$.

In this way, our paper takes a step forward with respect to Monfort et al. (2013), who conduct a similar analysis, but based on labour productivity. Not only do we identify the existence of clusters, but we also ascribe the identified convergence clubs to specific components of the RULCs, with labour productivity decomposed into capital intensity and technological components. This allows us to enrich the analysis on the sources of the lack of full convergence in Europe, in spite of decades of growing economic integration.

To take a first glance at the evolution in RULCs, Table 1 shows their cumulated evolution between 1979 and 2012. The first noticeable feature is the fall in all economies, which ranges from $5 \%$ to $25 \%$. This is a reflection of the systematic effort undertaken by these economies to become more competitive in a context of growing market pressures (acceleration in the globalisation process and deeper European integration).

It is also interesting to observe that the most intensive reductions have taken place in the Eurozone periphery. Ireland takes the lead, with a fall of 25 percentage points (pp) that is followed by some Club-Med countries-Greece, Portugal and Spain-with a fall around $20 \mathrm{pp}$. Then we find Italy (-15 pp.), which comes after Sweden. ${ }^{5}$ Thus, maybe surprisingly, the sometimes called PIIG economies, appear as those that have undergone the most intensive effort in controlling their RULCs. At the other extreme we observe continental European economies such as Finland and Belgium, with falls below $10 \mathrm{pp}^{6}$.

Given these differences, dating back to the 1980s, we do not support the idea that the inception of the Euro brought, inherently to the new monetary union, the development of unprecedented external imbalances. We rather see these imbalances as a reflection of a latent structural problem that was exacerbated in the context of a single currency and the impossibility of securing competitive gains through the prevailing, and convenient, management of the exchange rate.

Table 1 RULC in selected Eurozone economies

\begin{tabular}{llllllll}
\hline & $\mathbf{1 9 7 9}$ & $\mathbf{2 0 1 2}$ & $\mathbf{\Delta} \boldsymbol{V}$ & & $\mathbf{1 9 7 9}$ & $\mathbf{2 0 1 2}$ & $\mathbf{\Delta} \boldsymbol{\nabla}$ \\
\hline Ireland & 100.0 & 74.7 & -25.3 & Austria & 100.0 & 87.1 & -12.9 \\
Spain & 100.0 & 78.8 & -21.2 & Netherlands & 100.0 & 87.7 & -12.3 \\
Portugal & 100.0 & 80.0 & -20.0 & France & 100.0 & 89.0 & -11.0 \\
Greece & 100.0 & 81.8 & -18.2 & Finland & 100.0 & 92.1 & -7.9 \\
Sweden & 100.0 & 83.0 & -17.0 & Belgium & 100.0 & 95.2 & -4.8 \\
Italy & 100.0 & 85.1 & -14.9 & & & & \\
\hline
\end{tabular}

Source: Ameco Database. 
Our hypothesis is that the root of these imbalances is related to the specificities of the growth model in the periphery and core European countries. This hypothesis gets some initial support from a descriptive analysis showing that the periphery economies have mainly relied on capital intensification to counterbalance their otherwise smaller increase in wages. Increases in capital intensity are recognised to boost efficiency, but we argue that this is an inferior strategy than the one followed by the core economies, much more based on technological progress.

To check the validity of our hypothesis, our first target is to evaluate the existence of clusters in the RULCs of some Eurozone economies. The second target is to assess whether these clusters are driven by some of the components in which the RULCs can be decomposed. These are real wages, capital intensity, and technology, the latter two being the drivers of labour productivity and economic growth.

For the clusters to be examined, we first decompose the RULCs into these three components and compute their simulated trajectories when either one or two of the components take their actual values. This provides a first picture of the evolution of the Eurozone economies, in terms of the path followed by their RULCs. Three groups emerge. One with the Club-Med countries, which we classify as capital-intensity driven economies; another one with technology-driven economies such as Belgium, Finland, Ireland, the Netherlands, and Sweden; and a third one with balanced-growth driven economies, where capital intensity and technology have similar explanatory weights. Here we find Austria and France.

To evaluate the existence of clusters, we follow the methodology proposed by Phillips and Sul $(2007,2009)$ in which different convergence paths can be distinguished among heterogenous economies involved in a convergence process. As explained in Section 4, this heterogeneity is modelled through a nonlinear time varying factor model, which provides flexibility in idiosyncratic behaviour over time-convergence is a dynamic process - and across section-since we examine a group of 11 economies.

We find these features particularly appealing to examine the convergence process of the RULCs in the Eurozone. The main reason is that, although economies with different economic size and structure may appear to follow a similar development path, they may converge at different speeds and, therefore, may actually be at different stages of that same path. Moreover, although Phillips and Sul's $(2007,2009)$ modelling allows for idiosyncratic behaviour, it also retains some commonality across the panel. In particular, it allows to check the convergence to a constant of the heterogeneous time varying idiosyncratic components, in which case panel convergence holds.

The cluster analysis involves the actual series of the RULCs and all the simulated scenarios in which these costs are decomposed, each of them accounting for the influence of one, two or three of the RULCs components. We find a wide heterogeneity of clusters both in number-different scenarios deliver a different number of clusters-and composition-the composition of the clusters is not robust across simulations.

Given these results-the expected outcome after years of economic integration was, ex-ante, convergence to a single cluster in all major macroeconomic dimensions-we question the strategy, originally endorsed by the Maastricht Treaty, of securing nominal convergence without considering real convergence indicators. Rather, we suggest to consider both nominal and real convergence simultaneously in order to safeguard, or at least strengthen, today's hurt process of European integration. In this context, taking into 
account that it is the dispersion of total factor productivity, and not that of wage compensation, what has driven the lack of convergence in RULCs, labour market policies should be designed and coordinated to promote convergence in total productivity growth.

The rest of the paper is structured as follows. In Section 2, we present a decomposition of the RULCs, which is applied to a broad selection of Eurozone economies in Section 3. In Section 4, we explain the methodology we use for the cluster analysis. Section 5 presents our findings before discussing their major implications in Section 6. Section 7 concludes.

\section{Analytical decomposition}

To study its evolution over time, the real unit labour costs (RULC) can be decomposed in its relevant constituents.

We start by re-writing Equation (1) as

$$
R U L C_{t}=\frac{\text { Total real employment compensation }}{\text { Real output }} \frac{w_{t}}{y_{t}},
$$

where $w_{t}$ denotes real wages or, in other words, the nominal wages deflated by prices $\left(W_{t} / P_{t}\right)$. In turn, $y_{t}$ is real output or the nominal output also deflected by prices $\left(Y_{t} / P_{t}\right)$. Under the assumption of a production function with capital $K_{t}$, labour $L_{t}$, and technology $A_{t}$ as production factors, (nominal) output per employee $Y_{t} / L_{t}$ can be expressed as:

$$
\left(Y_{t} / L_{t}\right)=P_{t} * K_{t}^{\left(1-\alpha_{t}\right)} * A_{t},
$$

where $\alpha_{t}$ is the time-varying labour income share.

Inserting (3) in (2) and differentiating, the growth rate of real unit labour costs $\frac{\Delta\left(R U L C_{t}\right)}{R U L C_{t-1}}$ can be decomposed as a function of the trajectories of real wages, capital intensity, and technological progress.

$$
\frac{\Delta\left(R U L C_{t}\right)}{R U L C_{t-1}} \approx\left(\frac{\Delta\left(W_{t}\right)}{W_{t-1}}-\frac{\Delta\left(P_{t}\right)}{P_{t-1}}\right)-\left(1-\alpha_{t}\right) * \frac{\Delta\left(K_{t}\right)}{K_{t-1}}-\frac{\Delta\left(A_{t}\right)}{A_{t-1}} .
$$

The first term in Equation (4) accounts for the rise in the RULCs arising from increases in real compensation per employee. The second and third terms account, respectively, for the fall in the $R U L C_{t}$ resulting from growing capital intensity and quicker technological progress. It is important to note that these two terms $-\left(1-\alpha_{t}\right) * \frac{\Delta\left(K_{t}\right)}{K_{t-1}}$ and $\frac{\Delta\left(A_{t}\right)}{A_{t-1}}-$ are the driving forces of labour productivity, as written in Equation (1), and, hence, of economic growth.

Following this decomposition, Table 2 shows the three simulated scenarios that can be computed (we call them Simulations 1, 4 and 7 because new scenarios in between are added below, in Table 7). In Simulation 1, the RULCs only respond to changes in real wages (there is no progress in either capital deepening nor in technological change). In Simulation 4, they respond to real wages and capital intensity (and there is no technological progress). In Simulation 7, the three components are taken into account, and the resulting simulation can be interpretted as the overall fit of our decomposition to the actual data.

\section{Empirical decomposition}

\subsection{Data}

We use annual data obtained from the macro-economic database of the European Commission's Directorate General for Economic and Financial Affairs (DG ECFIN). Our 
Table 2 Simulated RULCs

\begin{tabular}{lllll}
\hline & $\frac{\Delta w_{t}}{w_{t-1}}$ & $\left(1-\alpha_{t}\right) \frac{\Delta K_{t}}{K_{t-1}}$ & $\frac{\Delta A_{t}}{A_{t-1}}$ & Outcome \\
\hline Simulation 1 & $\checkmark$ & - & - & $R \cup L C_{1 t}$ in the absence of capital \\
Simulation 4 & $\checkmark$ & $\checkmark$ & - & intensity and TFP. \\
Simulation 7 & $\checkmark$ & $\checkmark$ & & $R \cup L C_{4 t}$ in the absence of \\
& & & TFP. \\
& & & $R \cup L C_{7 t}$ accounted for by the \\
& & & three components (overall fit).
\end{tabular}

Note: See Table 7, where more scenarios are defined.

sample period runs from 1980 to 2012. Table 3 presents the variables used, together with the corresponding codes in the Ameco Database.

Figure A1 in the Additional file 1: Appendix 1. compares the actual growth rates of the RULCs with those obtained from the decomposition proposed in Equation (4). One relevant feature of this decomposition is the existence of non-negligible differences between the actual and the simulated trajectories of the RULCs in the 1960s and the 1970s. In levels, these differences end up producing significant discrepancies which would blur the picture obtained with the decomposition analysis. This is the reason why we have excluded these two decades and decided to depart in 1979 and focus on the changes occurred in the 1980s, 1990s, and 2000s. On one side, this still give us enough degrees of freedom to safely conduct the cluster exercise. On the other side, this restricts the analysis to the aftermath of the oil price shocks and excludes noise from the structural break that these shocks caused on all advanced economies.

\subsection{Evolution by components}

Table 4 shows the evolution of the RULCs (as in Table 1) and each of its components up to 2012 departing from an index value 100 corresponding to 1979. As we know from Table 1, the RULCs have fallen relatively more in the periphery economies than in the non-periphery ones. They have fallen by 19.9 per cent, on average, in Greece, Ireland, Italy, Portugal, and Spain, which is almost twofold the 10.6 per cent fall achieved, on average, by the others.

The larger reduction in the overall RULC index in the periphery coincides with a smaller increase in wages ( $44.5 \%$ vs. $51.7 \%$, respectively, each of the two areas) and a substantial larger increase in the capital intensity component (37.7 vs. 20.8 per cent). In contrast, the evolution of the TFP component in the Core economies has been much more dynamic, showing an average increase of 38.9 per cent, in clear contrast with the 17.8 per cent rise observed in the Mediterranean ones. Ireland is excluded from this last calculation, as it

Table 3 Definitions and codes

\begin{tabular}{lll}
\hline Variable & Notation & Code \\
\hline Real unit labour cost & RULC & QLCD \\
Nominal compensation per employee & $W$ & HWCDW \\
Labour income share & $\alpha$ & ALCD \\
Net capital stock at constant prices per person employed & $K$ & RKNDE \\
Total Factor Productivity & A & ZVGDF \\
Price deflator for Gross Domestic Product at market prices & $P$ & PVGD \\
\hline
\end{tabular}

Note: the Codes correspond to Ameco Database variables. 
Table 4 RULCs and components: index 100 = 1979 and values in 2012

\begin{tabular}{|c|c|c|c|c|c|c|c|}
\hline & \multirow[t]{2}{*}{1979} & \multicolumn{4}{|c|}{ Values in 2012} & \multirow[b]{2}{*}{$\frac{(I)}{(I I I)}$} & \multirow[b]{2}{*}{$\frac{(I I)}{(I I I)}$} \\
\hline & & $\frac{\Delta R U L C_{t}}{R U L C_{t-1}}$ & $\begin{array}{l}\frac{\Delta w_{t}}{w_{t-1}} \\
(I)\end{array}$ & $\begin{array}{l}\left(1-\alpha_{t}\right) \frac{\Delta K_{t}}{K_{t-1}} \\
(I I)\end{array}$ & $\begin{array}{l}\frac{\Delta A_{t}}{A_{t-1}} \\
(I I I)\end{array}$ & & \\
\hline \multicolumn{8}{|l|}{ Periphery } \\
\hline Greece & 100.0 & 81.8 & 104.7 & 129.5 & 100.2 & $104 \%$ & $129 \%$ \\
\hline Ireland & 100.0 & 74.7 & 197.2 & 138.6 & 189.6 & $104 \%$ & $73 \%$ \\
\hline Italy & 100.0 & 85.1 & 122.7 & 125.5 & 116.5 & $105 \%$ & $108 \%$ \\
\hline Portugal & 100.0 & 80.0 & 169.5 & 154.9 & 137.6 & $123 \%$ & $113 \%$ \\
\hline Spain & 100.0 & 78.8 & 128.3 & 139.8 & 116.9 & $110 \%$ & $120 \%$ \\
\hline Average & 100.0 & 80.1 & 144.5 & 137.7 & 132.2 & $109 \%$ & $109 \%$ \\
\hline \multicolumn{8}{|c|}{ Non-periphery } \\
\hline Austria & 100.0 & 87.1 & 152.4 & 129.7 & 133.9 & $114 \%$ & $97 \%$ \\
\hline Belgium & 100.0 & 95.2 & 148.3 & 118.0 & 129.4 & $115 \%$ & $91 \%$ \\
\hline Finland & 100.0 & 92.1 & 182.3 & 120.4 & 159.8 & $114 \%$ & $75 \%$ \\
\hline France & 100.0 & 89.0 & 137.9 & 126.7 & 122.9 & $112 \%$ & $103 \%$ \\
\hline Netherlands & 100.0 & 87.7 & 136.3 & 115.6 & 132.8 & $103 \%$ & $87 \%$ \\
\hline Sweden & 100.0 & 83.0 & 153.9 & 123.5 & 149.4 & $103 \%$ & $83 \%$ \\
\hline Average & 100.0 & 89.4 & 151.7 & 120.8 & 138.9 & $109 \%$ & $88 \%$ \\
\hline
\end{tabular}

Source: Own decomposition based on official European Commission data (Ameco Database). 
has been a clear exception with an important cumulative growth both in capital intensity and, especially, in TFP, with a 89.6 per cent increase.

Beyond the identification of these two groups, a further crucial result is that in none of these economies have wage progressed much beyond their sustainable growth. By sustainable growth we mean one that is consistent with the progress of technology.

Indeed, following any standard growth model, the reference wage growth would be set according to technological change so as to ensure a long-run balanced growth path. Denoting $\gamma_{a}$ as the growth rate of technology, $\gamma_{k}$ as the growth rate of capital accumulation (per employee), and $\gamma_{w}$ the growth rate of wages, a balanced growth path would satisfy:

$$
\gamma_{w}=\gamma_{k}=\gamma_{a}
$$

On this account it is worthwhile noting that the evolution of the periphery economies since the end of the 1970s is, in general, closer to the above standard theoretical rule. With the exception of Portugal, wages in these countries have evolved closer to the levels granted by technological progress than in most non-periphery countries. But this is not the only significant trait. It can also be observed that capital intensity has also progressed more, relative to technology, in the periphery (with the exception of Ireland) than in the non-periphery economies.

From these results, we draw the following preliminary conclusions. First, the relative trajectories of wages and capital intensity uncover the two channels by which the periphery countries have succeeded in reducing the RULCs by far more than the non-periphery ones. Second, we hypothesise that the problem underlying the lack of real convergence is not originated in the labour market but, rather, in the different speed of technological progress, which is what effectively leads wage setting and the capital accumulation process.

In addition, because the evaluation of these ratios is silent on the relative magnitude of each component's influence on the RULCs, we next look at the detailed contribution of each of these components to the evolution of the RULCs.

\subsection{Scenarios}

Figures 1, 2 and 3 group the 11 Eurozone economies considered according to the intensity at which the growth drivers-capital intensity and technological progress-have counterbalanced the rise in the RULCs stemming from real wage growth.

The black line depicts the actual trajectory, which is closely tracked by the line in green resulting from Simulation 7 in Table 2 (i.e., the one with the three components providing the overall fit of the decomposition). This is an indication that the decomposition analysis provides a faithful account of the incidence of each component in the aggregate evolution of the RULCs.

The blue line accounts for the upward effect that the growth in real wages exert, while the red line incorporates (on top of the effect of the growth in real wages) the downward influence of capital intensity. In this way, the distance in 2012 between the blue and the red lines is an indication of the cumulated counterbalancing effect of capital intensity on the RULCs since 1979, while the distance between the red and green lines is an indication of the incidence of technological progress. 
a Greece
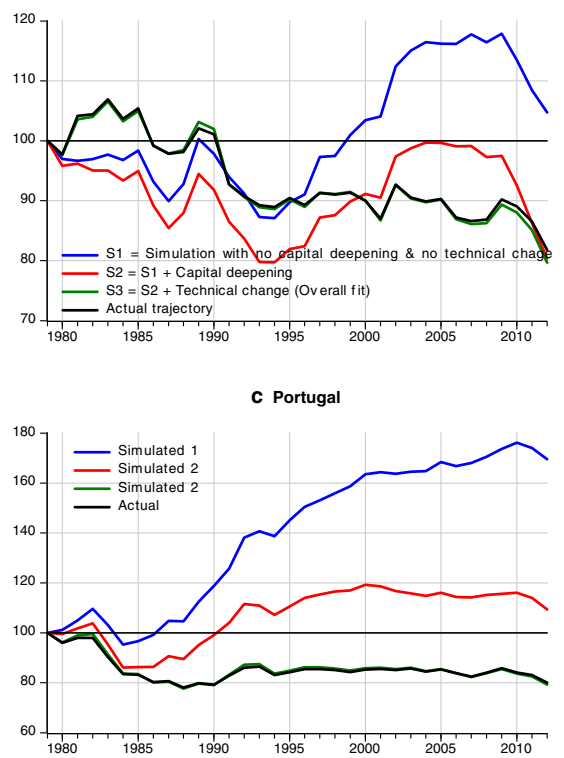

b Italy

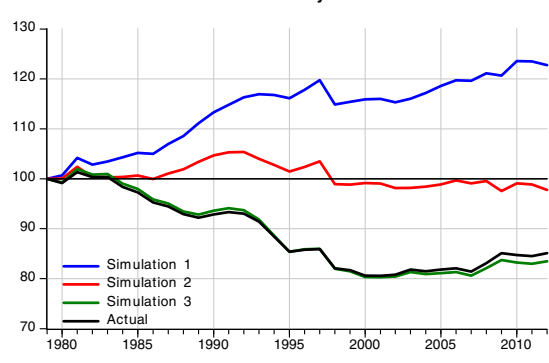

d Spain

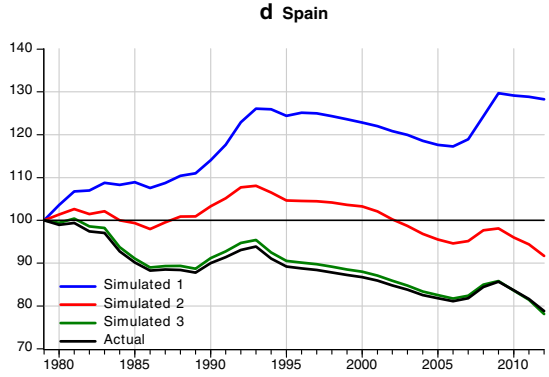

Figure 1 Capital-intensity driven economies. Source: Own decomposition based on official European Commission data (Ameco Database)

As it is the case for the countries plotted in Figure 1, proximity of the red and green lines is an indication that technological progress has been weak in last decades. This is the reason why these economies are grouped under the label of capital intensity driven economies.

In turn, in the economies plotted in Figure 2, the cumulative impact of technological progress is much wider and explains a much larger proportion than capital intensity of the shift from the RULCs when real wages are the only driving force to the actual lower value they take in 2012. These are, therefore, the group of technology driven economies with regard to the path followed by their RULCs.

Then in Figure 3 we have the two balanced driven economies in the sense that neither capital intensity nor technological progress dominate in explaining the downward trajectory of the RULCs, once accounting for the rise in real wages.

Table 5 provides more detailed information on the precise values of the RULCs under the scenarios considered. The first block of columns provides the final values taken by the RULCs under the different scenarios considered in Table 2 and plotted in Figures 1, 2, 3 (we call them A, B, and C). Note that the value in C, resulting from simulation 7 , is very close to the actual values of the RULCs in 2012 (in first column of Table 4).

The second block exploits this information to obtain the change in the RULCs due to the evolution of real wages $(=\mathrm{A}-100$, where 100 is the departing index value), of capital intensity $(=\mathrm{B}-\mathrm{A})$, and technological progress $(=\mathrm{C}-\mathrm{B})$. It can be observed that, with the exception of Portugal, the Club-Med economies experienced relatively mild increases in the RULCs in response to real wages-below 30 percentage points. On the contrary, in the rest of economies this value was above 30 percentage points. This contrasted patterns is a reflection of differences in the progress of labour productivity.

The sources of these differences can be assessed by looking at the contributions of the two growth drivers, capital intensity and technological change ${ }^{7}$. On this account, no clear 


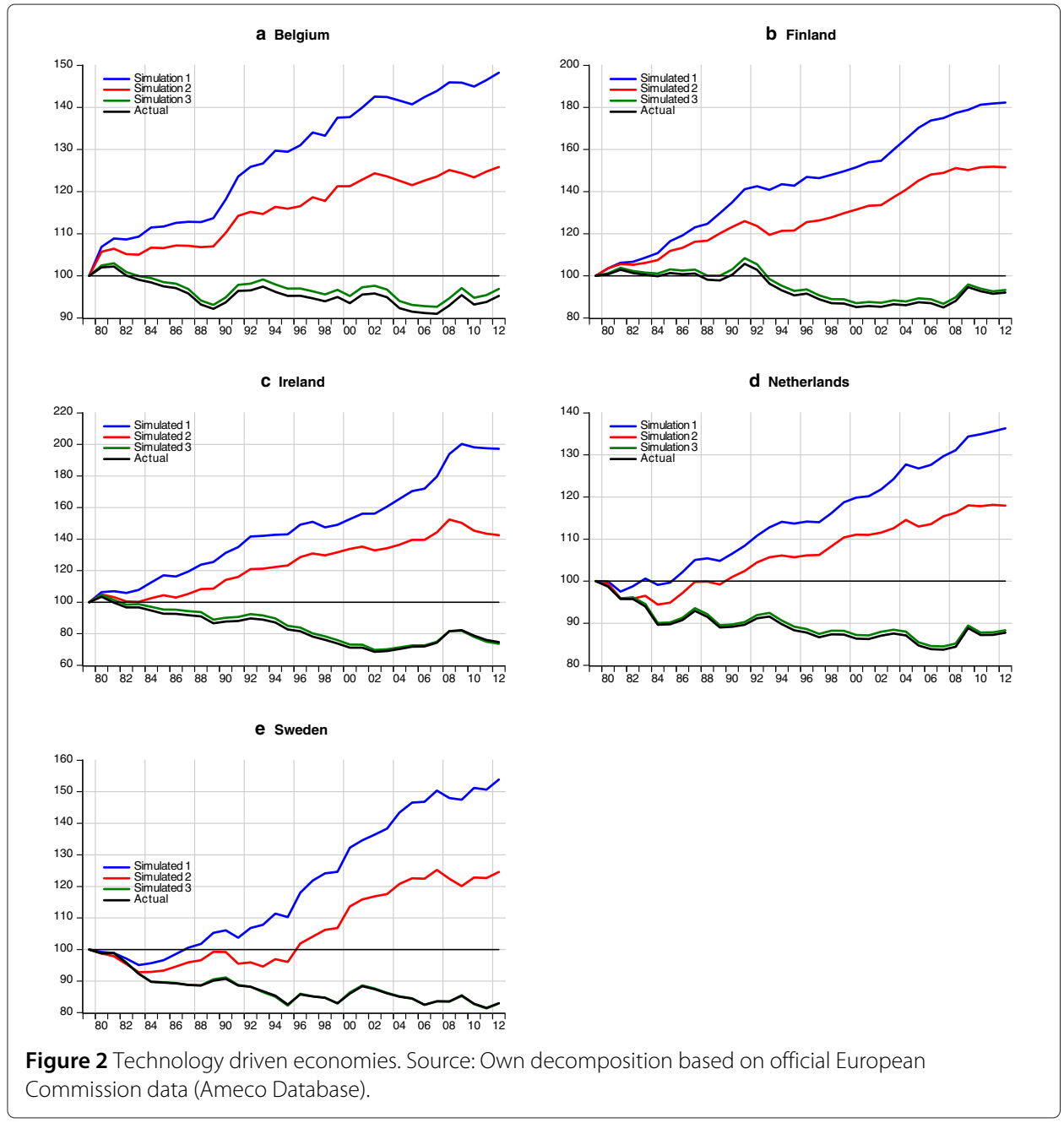

pattern can be perceived when looking at the role played by capital intensity in percentage point changes. In particular, with the exception of Portugal, the rest of the Club-Med countries have values between -24 and $-37 \mathrm{pp}$, whereas (with the exception of Ireland), the rest of economies have values between -18 and -35 . There is, therefore, a relatively homogeneous impact of the progress in capital accumulation on the reduction of the RULCs in the late decades across Eurozone countries.

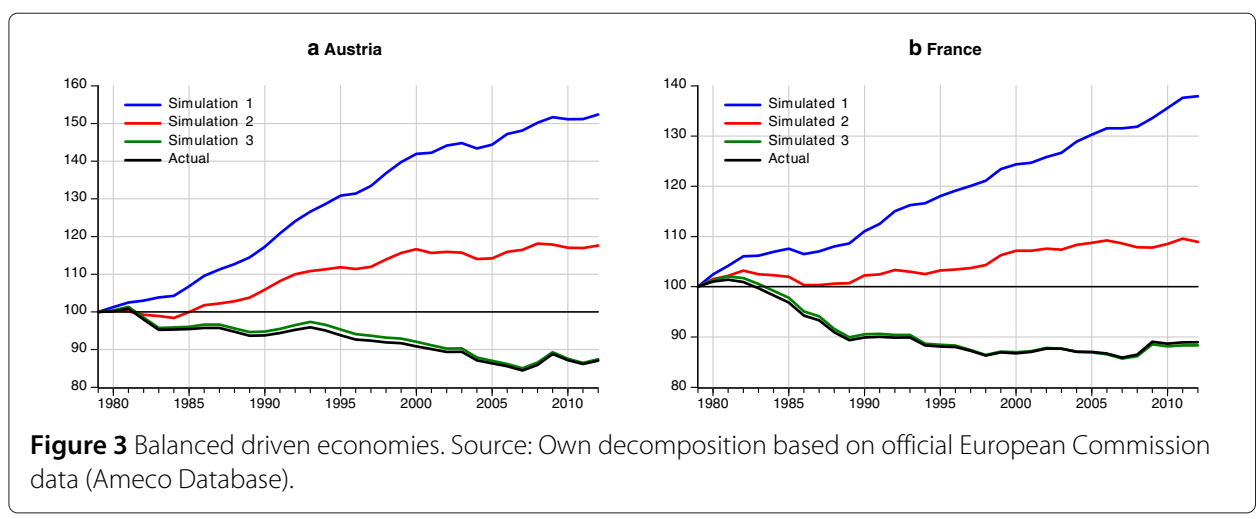


Table 5 RULCs and components

\begin{tabular}{|c|c|c|c|c|c|c|c|c|}
\hline & \multicolumn{3}{|c|}{ Simulations } & \multicolumn{3}{|c|}{ Changes explained by: } & \multicolumn{2}{|c|}{$\%$ Growth drivers* } \\
\hline & $\begin{array}{l}\text { S1 } \\
\text { (A) }\end{array}$ & $\begin{array}{l}\text { S4 } \\
\text { (B) }\end{array}$ & $\begin{array}{l}\text { S7 } \\
\text { (C) }\end{array}$ & $\begin{array}{l}w_{t} \\
(\mathrm{~A}-100)\end{array}$ & $\begin{array}{l}\left(1-\alpha_{t}\right) K_{t} \\
(\mathrm{~B}-\mathrm{A})\end{array}$ & $\begin{array}{l}A_{t} \\
\text { (C-B) }\end{array}$ & $\frac{(B-A)}{(A-C)}$ & $\frac{(C-B)}{(A-C)}$ \\
\hline \multicolumn{9}{|c|}{ Capital-intensity driven gains in RULCs } \\
\hline Greece & 104.7 & 80.3 & 79.7 & 4.7 & -24.4 & -0.7 & 97.4 & 2.6 \\
\hline Italy & 122.7 & 97.8 & 83.5 & 22.7 & -25.0 & -14.3 & 63.6 & 36.4 \\
\hline Portugal & 169.5 & 109.4 & 79.3 & 69.5 & -60.1 & -30.1 & 66.7 & 33.3 \\
\hline Spain & 128.3 & 91.7 & 78.1 & 28.3 & -36.6 & -13.6 & 73.0 & 27.0 \\
\hline \multicolumn{9}{|c|}{ Technology driven gains in RULCs } \\
\hline Belgium & 148.3 & 125.8 & 96.9 & 48.3 & -22.4 & -28.9 & 43.7 & 56.3 \\
\hline Finland & 182.3 & 151.6 & 93.2 & 82.3 & -30.7 & -58.3 & 34.5 & 65.5 \\
\hline Ireland & 197.2 & 142.5 & 73.6 & 97.2 & -54.7 & -68.9 & 44.3 & 55.7 \\
\hline Netherlands & 136.3 & 118.0 & 88.3 & 36.3 & -18.3 & -29.7 & 38.2 & 61.8 \\
\hline Sweden & 153.9 & 124.6 & 82.8 & 53.9 & -29.3 & -41.7 & 41.2 & 58.8 \\
\hline \multicolumn{9}{|c|}{ Balanced driven gains in RULCs } \\
\hline Austria & 152.4 & 117.6 & 87.4 & 52.4 & -34.8 & -30.2 & 53.5 & 46.5 \\
\hline France & 137.9 & 109.0 & 88.3 & 37.9 & -29.0 & -20.6 & 58.4 & 41.6 \\
\hline
\end{tabular}

Notes: S1, S4 and S7 correspond to Simulations 1, 4, and 7, as defined in Table 2; *indicates the relative share of capital intensity and technological progress on the overall downward impact of these growth drivers on RULCs. Source: Own decomposition based on official European Commission data (Ameco Database). 
The main difference, in this context, can be found in the contribution of technological progress to the fall of these costs, which has been very poor in the Club-Med economies (bar Portugal), but large in the other ones (bar France, which is in between the two groups and, on this respect, resembles its Mediterranean neighbours). This can be easily seen through the third block of columns in Table 5 , where information is provided on the relative share of capital intensity and technological progress in explaining the overall downward contribution of these growth drivers to the fall of the RULCs.

In the Club-Med economies, the fall in RULCs have been mainly driven by progress in capital intensity which accounts, at least, for $66.3 \%$ of the fall as in Italy. This leaves technological progress to account, on average, in Italy, Portugal, and Spain, for a third of the fall in the RULCs. Greece is an extreme case where the contribution of TFP has been almost non-existent.

Belgium, Finland, Ireland, the Netherlands, and Sweden have in common a contribution of TFP which is explains at least $55 \%$ of the fall, and reaches two thirds in Ireland. This is the group of economies with technology driven gains in RULCs.

Finally, Austria and France take an intermediate position with a balanced contribution of the growth drivers to the fall in RULCs. The capital intensity share is around 55\%, and thus significantly lower than in the Club-Med economies, while the share of technological progress is around $45 \%$, and thus significantly lower than in the Nordic and Continental European countries.

From this analysis, we conclude that differences in the speed of technological progress is a major determinant of the unlikely evolution of the RULCs in the Eurozone countries. Note that this conclusion is endorsed by the prediction, from any standard neoclassical growth model, that technology is the key growth driver and, hence, the critical factor allowing for capital accumulation and wage growth in the long-run. To confirm this finding, we now turn to a cluster analysis seeking to classify these economies into significantly homogeneous groups according to the individual and joint influence of the RULCs components.

\section{Cluster analysis}

The panel data model by Phillips and Sul (2007) has been proposed to represent the behaviour of economies in transition allowing for different convergence paths with heterogeneous individuals. Heterogeneity is formulated as a nonlinear time varying factor model which provides flexibility in idiosyncratic behaviour over time and across section. These features of the model are very appealing in the case of convergence in the euro Eurozone. Countries with different economic sizes and structures may appear to follow a similar development path but at different speeds so that they are currently at different stages on that path. The effect on technological and capital accumulation caused by the different economic policies in different countries may also be important to explain different speeds of convergence. The model allows for idiosyncratic behaviour and also retains some commonality across the panel, meaning that when the heterogeneous time varying idiosyncratic components converge over time to a constant, panel convergence holds.

Phillips and Sul (2007) decompose the variable of interest in two components, one common, $\mu_{t}$, and one idiosyncratic, $\delta_{i t}$, both of which are time-varying. This formulation incorporates the possibility of transitional heterogeneity or even transitional divergence 
and enables testing for convergence by testing whether the factor loadings $\delta_{i t}$ converge (see Additional file 2: Appendix for details).

The convergence approach by Phillips and Sul (2007) presents clear advantages. First, it is a test for relative convergence as it measures convergence to some cross-sectional average in contrast to the concept of level convergence analysed by Bernard and Durlauf (1995). Second, this approach outperforms the standard panel unit root tests since in the latter case $X_{i t}-X_{j t}$ may retain nonstationary characteristics even though the convergence condition holds. In other words, a panel unit root test may classify the difference between gradually converging series as non-stationary. As a further problem, a mixture of stationary and non-stationary series in the panel may bias results. Moreover, test results are sometimes not particularly robust. In contrast, the Phillips and Sul (2007) test does not depend on any particular assumption concerning trend stationarity or stochastic nonstationarity of the variables to be tested.

\section{Clusters in the RULCs and its components}

Our cluster analysis involves the evaluation of several scenarios. The first one is the analysis on the actual trajectory of the RULCs, which is followed by the analysis on the seven simulated trajectories of the RULCs presented in Table 6. In Simulations 1, 2 and 3, the RULCs only respond to changes in one of the components. These are, respectively, real wages (there is no progress in either capital deepening nor in technical change), capital intensity (there is no growth in real wages nor in TFP), and technological change (real wages and capital intensity do not change). In Simulations 4, 5 and 6, RULCs respond to two out of the three components. As noted before, in the first of these, real wages and capital intensity (but not technological progress) are taken into account; in the second one (Simulation 5) real wages and TFP (but not capital intensity) are considered, whereas Simulation 6 assumes no growth in real wages. Simulation 7 takes into account the influence of the three components and accounts for the overall fit of the decomposition.

Table 6 RULCs: actual and simulated

\begin{tabular}{|c|c|c|c|c|c|}
\hline & $\frac{\Delta R U L C}{R U L C_{t-1}}$ & $\frac{\Delta w_{t}}{w_{t-1}}$ & $\left(1-\alpha_{t}\right) \frac{\Delta K_{t}}{K_{t-1}}$ & $\frac{\Delta A_{t}}{A_{t-1}}$ & Outcome \\
\hline Actual & $\checkmark$ & - & - & - & Clusters on actual aggregate data. \\
\hline Simulation 1 & - & $\checkmark$ & - & - & $\begin{array}{l}\text { RULC } 1 t \text { in the absence of capital } \\
\text { intensity and TFP. }\end{array}$ \\
\hline Simulation 2 & - & - & $\checkmark$ & - & $\begin{array}{l}\text { RULC } C_{2 t} \text { in the absence of real } \\
\text { wages and TFP. }\end{array}$ \\
\hline Simulation 3 & - & - & - & $\checkmark$ & $\begin{array}{l}R U L C_{3 t} \text { in the absence of real } \\
\text { wages and capital intensity. }\end{array}$ \\
\hline Simulation 4 & - & $\checkmark$ & $\checkmark$ & - & $R U L C_{4 t}$ in the absence of TFP. \\
\hline Simulation 5 & - & $\checkmark$ & - & $\checkmark$ & $\begin{array}{l}R_{U L C} C_{5 t} \text { in the absence of } \\
\text { capital intensity. }\end{array}$ \\
\hline Simulation 6 & - & - & $\checkmark$ & $\checkmark$ & $\begin{array}{l}R U L C_{6 t} \text { in the absence of real } \\
\text { real wages. }\end{array}$ \\
\hline Simulation 7 & - & $\checkmark$ & $\checkmark$ & $\checkmark$ & $\begin{array}{l}R \cup L C_{7 t} \text { accounted for by the } \\
\text { three components (overall fit). }\end{array}$ \\
\hline
\end{tabular}


Detailed information on the results of the cluster analysis for each of these scenarios is presented in Additional file 2: Appendix 2. Table 7 summarises the outcome of this analysis when applied to the scenarios described in Table 6. Regarding the actual values of the RULCs, our results uncover the existence of two groups, one comprising Austria, Belgium, Finland, France, and the Netherlands belonging to the continental Europe, and another one comprising the so-called PIIGS (Portugal, Ireland, Italy, Greece, and Spain) plus Sweden. The PIIGS group is characterised by structural difficulties to compete internationally, and a regular use of the exchange rate-in the pre-EMU era-to compensate for their positive inflation differentials with respect to their main trade partners. Interesting enough, this was also the case of Sweden up to 1990 (see Freeman et al. 2010).

Note that these results are consistent with our decomposition analysis. The first cluster includes three economies with technology-driven gains in the RULCs, plus the group with balanced driven gains, while the second cluster incorporates the four countries characterised by capital-intensity driven gains. This second cluster includes, in addition, Ireland and Sweden.

Regarding Simulation 1, the first group identified in the cluster analysis puts together Finland, Ireland, and Portugal. This should come as no surprise since these are the economies that during the 1980s, 1990s and 2000s have experienced, by far as shown in Table 2, the largest growth in real wages. The second and third groups comprise, respectively, Austria, Belgium and Sweden and, then, France and the Netherlands, while the last one gathers Greece, Italy and Spain together.

Table 7 Clusters

\begin{tabular}{|c|c|c|c|c|c|c|c|c|}
\hline & Actual & $\operatorname{Sim} 1$ & $\operatorname{Sim} 2$ & $\operatorname{Sim} 3$ & $\operatorname{Sim} 4$ & $\operatorname{Sim} 5$ & $\operatorname{Sim} 6$ & $\operatorname{Sim} 7$ \\
\hline \multirow{6}{*}{ Group 1} & & & & & & & $\mathrm{AU}$ & \\
\hline & & & & & & & $\mathrm{BE}$ & \\
\hline & $\mathrm{AU}$ & & & $\mathrm{FR}$ & & & $\mathrm{FR}$ & $\mathrm{AU}$ \\
\hline & $\mathrm{BE}$ & $\mathrm{FI}$ & $\mathrm{BE}$ & GR & $\mathrm{FI}$ & $\mathrm{BE}$ & $G R$ & $\mathrm{BE}$ \\
\hline & $\mathrm{FI}$ & IR & $\mathrm{FI}$ & $\mathrm{IT}$ & IR & $\mathrm{PO}$ & $\mathrm{IT}$ & $\mathrm{Fl}$ \\
\hline & FR & $\mathrm{PO}$ & NT & SP & & & NT & $\mathrm{FR}$ \\
\hline \multirow{11}{*}{ Group 2} & NT & & & & & & $\mathrm{PO}$ & NT \\
\hline & & & & & & & $\mathrm{SP}$ & \\
\hline & & & & & & $\mathrm{AU}$ & & \\
\hline & GR & & & & & $\mathrm{FR}$ & & $G R$ \\
\hline & IR & & & $\mathrm{AU}$ & $\mathrm{AU}$ & $\mathrm{FI}$ & & IR \\
\hline & $\mathrm{IT}$ & $\mathrm{AU}$ & $G R$ & $\mathrm{BE}$ & $\mathrm{BE}$ & GR & $\mathrm{FI}$ & $\mathrm{IT}$ \\
\hline & $\mathrm{PO}$ & $\mathrm{BE}$ & $\mathrm{IT}$ & NT & NT & $\mid R$ & $\mid R$ & $\mathrm{PO}$ \\
\hline & $\mathrm{SP}$ & SW & SW & $\mathrm{PO}$ & $\mathrm{PO}$ & $\mathrm{IT}$ & SW & $\mathrm{SP}$ \\
\hline & SW & & & & SW & NT & & SW \\
\hline & & & & & & $\mathrm{SP}$ & & \\
\hline & & & & & & SW & & \\
\hline \multirow{4}{*}{ Group 3} & & & & & $\mathrm{FR}$ & & & \\
\hline & & $\mathrm{FR}$ & $\mathrm{AU}$ & $\mathrm{FI}$ & $G R$ & & & \\
\hline & & NT & $\mathrm{FR}$ & IR & $\mathrm{IT}$ & & & \\
\hline & & & & SW & SP & & & \\
\hline \multirow{3}{*}{ Group 4} & & $G R$ & IR & & FR & & & \\
\hline & & $\mathrm{IT}$ & $\mathrm{PO}$ & & & & & \\
\hline & & SP & $S P$ & & & & & \\
\hline
\end{tabular}


The classification in terms of capital intensity (Simulation 2) delivers groups that are not as different from one another than those obtained from Simulations 1 and 3. The reason is that, for real wages and TFP, there is much more dispersion in the evolution of the countries, than for capital intensity (see Table 2$)^{8}$. In any case, the most remarkable feature regarding capital intensity is that group 3 clearly identifies Austria and France as comprising a group themselves, while group 1 comprises only technology-driven economies (Belgium, Finland and the Netherlands).

The cluster analysis performed when TFP is the only variable allowed to affect the evolution of the RULCs (Simulation 3) provides useful complementary information which exploits wider differentials in the performance of the economies. Looking at the clusters, it is worthwhile pointing out that the first group does fully coincide with one of the clusters obtained from Simulation 4. The second and third ones, in turn, provide a very close match. The only difference is that Sweden moves from the second group (when both capital intensity and TFP are allowed to vary) to the third one (when only TFP changes).

We interpret this close match as evidence that TFP is the strongest driver of labour productivity, and, as such, growth policies deserve great attention from policy makers. This idea is consistent with the recent finding by Wierts et al. (2014) that the effect of the real exchange rate on exports in the Eurozone becomes smaller the higher the share of high technology exports in total exports. Following this, specialisation in high tech sectors pushes productivity and makes these economies less dependant of the real effective exchange rate, which, in the absence of national currencies, is the relevant variable to assess price competitiveness.

The contrast between the results under Simulations 1 and 3 virtually vanish in Simulation 5, in which the RULCs are evaluated considering changes in wages (like in Simulation 1) and TFP (as in Simulation 3). The first club joins Belgium and Portugal, while a second one contains the rest of the economies, although, in any case, we must state that the differences between the two clubs are of minor order (recall that Belgium and Portugal are the two countries where the ratio between wages and technology growth has been the largest-even though very close to the next economies in this ranking in the Belgian case).

Simulation 6 examines the clusters when both capital intensity and technology, but not wages, drive the evolution of the RULCs. This implies that the two sources of labour productivity are considered together. Since wages are fixed as a function of productivity, the less clubs we find, the more homogeneous will be wage growth in the Eurozone.

This sixth scenario is the only one in which we find two clear clusters. On top of this being the number of clusters obtained for the actual evolution of the RULCs, these clubs have a salient feature. The first one contains the members of cluster 1 and 2 under Simulation 3 (when technology was absent), while the second one exactly matches club 3 in Simulation 3. In other words, as opposed to capital intensity, technology seems to be the fundamental driving force in the clustering of the countries and, therefore, in the real convergence process.

To summarise, the actual path of the RULCs delivers two clusters which, in broad-brush terms coincide with the periphery and non-periphery Eurozone groups that have characterised the Sovereign-Debt crisis in 2010-2013. However, a wide variety of clusters emerge when these economies are examined according to the incidence of wages, capital intensity and technology on the RULCs. Four clusters exist in the first two simulations in which 
only wages or capital intensity affect the RULCs (with a different country-composition of these four clusters), but three when only technology is allowed to change. Three exist in the absence only of TFP changes, but two in the absence of capital intensity and real wages influences (although these two are different among them, and also relative to the two clubs resulting from the aggregate analysis).

\section{The intertwinement of labour and macroeconomic policy outcomes}

Our analysis has taken into account more than three decades of the recent economic history. The different countries studied include those in which the European integration process consolidated along the European Free Trade Association (EFTA) set up in 1960-with Austria, Portugal, and Sweden, and also Finland since 1961, among other countries-and the European Economic Community (EEC) - with Belgium, France, Italy and the Netherlands since the 1950s, and also Ireland (since 1973), Greece (1981), and Spain (1986) - to which the EFTA economies joined subsequently.

In a globalised world with deep economic integration, one could have expected a strong enough process of economic convergence so as to deliver a unique cluster. Beyond that, one could even envisage a situation in which this club would be the same for all the scenarios considered, with technology leading the convergence in all major macro variables.

It is clear, however, that the Eurozone economies are actually far from such theoretical prediction. Although we have verified that wages have grown in a sustainable manner all around following technological progress, their evolution is very heterogeneous as a reflection of the variety of technological experiences. This is what we observe when clustering systematically the RULCs so as to account for the incidence of one or two of the components that determine their trajectory.

Already in the aftermath of the Great Recession, analysts and policy makers enquire on the best policies to solve labour market problems such as long-run and youth unemployment, which affect the European economies asymmetrically. According to Krause et al. (2014), experts think that the effects of the Great Recession is a long-lasting phenomenon. Although our policy recommendations arise from the long-run perspective undertaken in the analysis (going, as such, beyond a conjunctural appraisal), it fully coincides with the diagnosis that current labour market problems are here to stay.

What is then the best policy response to deal with these long-lasting problems?

Within the Eurozone, the impossibility to embark into competitive devaluations has rendered the leadership to internal devaluations. In this way, labour market reforms enforcing wage moderation have been one of the pillars of the policy response. On one side, these reforms are expected to allow employment to recover, while, on the other one, they should also help economic growth by boosting net foreign demand. Accordingly, wage moderation is seen as a very tempting response to the crisis, both at the labour market and at macroeconomic levels (even more so in a context of austerity and ineffective standard monetary policy).

In contrast to this common view, recent evidence outlines the difficulties of succeeding in these policies in the Eurozone. Galí and Monacelli (2014), for example, show that the relationship between wage flexibility and employment stability is connected to the policy management of the exchange rate. This allows them to show that wage adjustments are much more ineffective in a currency union such as the EMU (where most trade occurs between economies with a fixed exchange rate) than in countries with a floating 
exchange rate and full control of their policies. Wage flexibility is not, therefore, such a promising tool.

Our results point in another direction and align with those of Pancotto and Pericoli (2014), who show that the introduction of the Euro has increased divergence in unit labour costs. Not only this, but; when looking at the sources of this growing divergence, it is the dispersion of productivity and not wage compensation that drives the process. This suggests that "persisting idiosyncratic dynamics are driven by real factors, i.e. diverging technological patterns, rather than by monetary factors, expressed by wage compensation" [Pancotto and Pericoli, 2014, p. 371].

This assessment is fully consistent with our results and lead us to claim that, together with conventional labour policies (in particular, the standard well known active labour market policies, ALMPs), complementary policy measures should support total factor productivity growth. By this, we are not only signalling standard measures such as R\&D expenditures and explicit support to innovation and patent applications. We also refer to other qualitative factors intimately related to the labour market, such as on-the-job training, which has been proven to be a significant booster of aggregate productivity at the European level (Sala and Silva 2013).

In this context it is worth distinguishing between generic subsidies in the form of training courses for the unemployed from on-the-job training directly targeted to the needs of the firm. In a recent study by Stokey (2015), policies that promote technology inflows are shown to be much more effective than subsidies to human capital accumulation in accelerating growth. In addition, differences in technology are critical for explaining differences in income levels over time and across economies. This is relevant for our investigation because it allows us to rationalise the enormous differences observed in economic outcomes across countries and over time, like the ones we have uncovered in the evolution of the RULCs.

Of course, this reasoning does not preclude the economies to improve the institutional framework in which their labour market operates. Our point is that, given that the labour market does not operate in isolation, technological factors cannot be neglected if these economies seek to converge to the leading club. And even in the case that labour market reforms limiting the scope of wage growth are judged to be inescapable, it is still true that these reforms will be much easier to implement if the economy secures a high growth in labour productivity 9 .

\section{Conclusion}

Were the Eurozone economies hiding structural differences in competitiveness through a skillful management of the exchange rate? Could this strategy no longer be hidden-and thus maintained-with the single currency, and then materialised in the form of unprecedented external imbalances? The results of this paper point to positive answers to these questions.

We have shown that the RULCs have fallen almost twice as much in the Periphery than in the non-Periphery countries over the period 1979-2012. This is the outcome of a less expansionary wage growth process mainly counterbalanced through capital intensity gains. On the contrary, Core Eurozone economies have experienced larger rates of wage growth sustained through a much more dynamic process of technological progress. 
Which one is the best strategy? Although capital accumulation boosts growth and productivity, technology is the right way to ensure stable long-run economic growth. This would explain why, in spite of the PIIGS effort to reduce their RULCs, they were unable to converge to the Core Eurozone economies.

The last decades have witnessed a period of the most intensive economic integration within Europe. Real convergence, however, has not been achieved as ex-ante expected. Instead of finding a single cluster or, at least, a robust configuration of clubs within the Eurozone, we have uncovered a variety of statistically significant clusters with, on top, wide country-variation in their composition.

Cluster heterogeneity, and lack of robustness in cluster composition, would have been such unexpected outcomes had the architects of the Economic and Monetary Union (EMU) been asked in 1989 Madrid's summit whether this process would result, 25 years later, into significant real convergence.

On the contrary, there was a quick and intensive deterioration of the current account balance in the PIIGS since the mid 1990s, which accelerated since the inception of the euro, and had a positive counterpart in the Core group current accounts. Our results lead us to think that the EMU has not been the cause of the external imbalances and the resulting sovereign-debt crisis in a context of closed financial markets. Rather, it has boosted some structural divergencies that were already present in the growth model of these economies.

Since these divergencies can be ascribed mainly to different technological levels rather than to a wrong wage behaviour in the Periphery, internal devaluation policies are not the solution to surpass the current situation in the Eurozone. These policies have forced rebalancing of the external deficits, but they do not help convergence. And the reason is the same we have heard many times when economies embark into external devaluations: these are not genuine competitive gains, it is technology that matters. Hence, the need is to widen the scope of labour market policies to emphasise productivity growth, for example, through a renewed focus on on-the-job-training.

\section{Endnotes}

${ }^{1}$ That is, convergence in prices: inflation (the price of goods and services), interest rates (the price of money), and exchange rate stability (the price of currencies), apart from the commitment to keep public sector accounts fairly balanced.

${ }^{2}$ The current euro crisis is considered by many observers as a crisis of government deficits and debt. Nevertheless, even a casual look at the data raises many doubts regarding this point of view (Hein et al. 2012). The ratio of gross government debt to GDP was only $25 \%$ in Ireland and $36 \%$ in Spain, whereas Portugal used to have a smaller debt burden than Germany. This ratio was far below $60 \%$, the reference value of the Stability and Growth Pact (SGP) in all three countries. Nobody would have suspected any risk of government default in these countries.

${ }^{3}$ By Periphery countries we mean Greece, Ireland, Italy, Spain, and Portugal, while the Core economies are Austria, Belgium, Finland, France, the Netherlands, and Sweden. Germany is not be considered since disaggregated data is only available 1991 onwards due to the unification process.

${ }^{4}$ The RULCs can also be conceived as the Unit Labour Costs (ULC) deflated by prices $(P)$ :

$$
R U L C=\frac{U L C}{P} \text { where } U L C=\frac{\text { Nominal compensation per employee }}{\text { Real labour productivity }} .
$$


${ }^{5}$ For a comprehensive analysis of the structural changes undergone by the Swedish economy, see Freeman et al. (2010).

${ }^{6}$ Germany shows a fall of less than $12 \mathrm{pp}$, very close to the fall experienced by the Netherlands.

${ }^{7}$ Note that the addition of the values in the second block of columns gives essentially the same information as Simulation 7 (the C column). In the case of Greece, for example, 4.7-(-24.4)-(-0.7)=-20.3, which is the fall in the RULC explained by our decomposition analysis (from 100 to 79.7, which is the value in the C column).

${ }^{8}$ More precisely, note that for real wages and TFP the countries with the smallest and biggest growths are Greece and Ireland, with differences around 90 percentage points. In contrast, for capital intensity the divergence across economies is in the much narrower range of 40 percentage points (between 115.6 in 2012 in the Netherlands and 154.9 in Portugal).

${ }^{9}$ This argument is used in Blanchard (2007) when assessing the policy options of Portugal to improve its economic situation in the euro context.

\title{
Additional files
}

Additional file 1: Appendix 1. Actual and simulated RULC.

Additional file 2: Appendix 2. Phillips and Sul $(2007,2009)$ methodology.

\section{Competing interests}

The IZA Journal of European Labor Studies is committed to the IZA Guiding Principles of Research Integrity. The authors declare that they have observed these principles.

\section{Acknowledgements}

We acknowledge helpful comments from an anonymous referee. Javier Ordóñez acknowledges financial support from the Spanish Ministry of Economy and Competitiveness through grant ECO2014-58991-C3-2-R, the Universitat Jaume I grant P1.1B2014-17 and the Generalitat Valenciana project PROMETEOII/2014/053. Hector Sala and José I. Silva are grateful to the Spanish Ministry of Economy and Competitiveness for financial support through grant ECO2012-31081.

Responsible editor: Alan Barrett

\begin{abstract}
Author details
${ }^{1}$ Departament d'Economia, Universitat Jaume I, Campus Riu Sec, 12071 Castelló, Spain, Institute of International Economics, Universitat Jaume I and Universidad Popular Autónoma del Estado de Puebla (UPAEP), Puebla, Mexico. ${ }^{2}$ Department d'Economia Aplicada, Universitat Aut ònoma de Barcelona, 08193 Bellaterra, Spain. ${ }^{3}$ Serra Húnter Fellow, Departament d'Economia, Universitat de Girona, Campus Montilivi, 17071 Girona, Spain.
\end{abstract}

Received: 29 September 2014 Accepted: 30 March 2015

Published online: 24 July 2015

\section{References}

Bernard A, Durlauf SN (1995) Convergence in international outputs. J Appl Econometrics 10(2):97-108

Blanchard OJ (2007) Adjustment within the euro. The difficult case of Portugal. Port Econ J 6:1-21

Croci Angelini E, Farina F (2012) Current account imbalances and systemic risk within a monetary union Vol. 83. pp 647-656

Freeman RB, Swedenborg B, Topel RH (2010) Reforming the welfare state: recovery and beyond in Sweden. NBER, The University of Chicago Press, Chicago

Galí J, Monacelli T (2014) Understanding the Gains from Wage Flexibility: The Exchange Rate Connection. CEPR Discussion Paper No. 9806, London, UK

Hein E, Truger A, van Treeck T (2012) The European Financial and Economic Crisis: Alternative Solutions from a (Post-)Keynesian Perspective. In: Arestis P, Sawyer M (eds). The Euro Crisis. Palgrave Macmillan, Basingstoke

Krause A, Rinne U, Zimmermann KF (2014) How Far Away Is a Single European Labor Market?. IZA Discussion Paper No. 8383, Bonn, Germany

Monfort M, Cuestas JC, Ordóñez J (2013) Real convergence in Europe: a cluster analysis. Econ Model 33:689-694

Pancotto F, Pericoli FM (2014) Till labor cost do us part: On the long run convergence of EMU countries. Int Econonomics Econ Policy 11:371-395

Phillips P, Sul D (2007) Transition modeling and econometric convergence tests. Econometrica 75:1771-1855

Phillips, P, Sul D (2009) Economic transition and growth. J Appl Econ 24:115-1185 
Sala H, Silva JI (2013) Labor productivity growth and vocational training: evidence from Europe. J Productivity Anal 40(1):31-41

Sinn H-W (2014) Austerity, growth and inflation: Remarks on the Eurozone's Unresolved competitiveness problem. World Econ 37(1):1-13

Stokey NL (2015) Catching up and falling behind. J Econ Growth 20:1-36

Wierts P, Van Kerkhoff H, de Haan J (2014) Composition of exports and export performance of Eurozone countries. J Common Market Stud 52(4):928-941

Submit your manuscript to a SpringerOpen ${ }^{\circ}$ journal and benefit from:

- Convenient online submission

- Rigorous peer review

- Immediate publication on acceptance

- Open access: articles freely available online

- High visibility within the field

- Retaining the copyright to your article

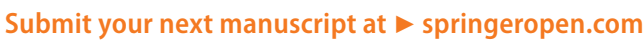

